pouch. It passed from here under the arch of the aorta and united with the right innominate vein at the right side of the arch of the aorta to form the superior vena cava, which opened as usual into the right auricle. Its tributaries were quite normal. The other venous trunks in the mediastina were normal. The left upper azygos vein was of small size. The left vagus nerve, descending in front of the left subclavian artery, passed between it and the left innominate vein, and then took up its position behind the root of the lung. It gave off the left recurrent laryngeal nerve immediately below the junction of the ductus arteriosus and the pouch from which the subclavian was derived. This nerve passed upwards and inwards, curved round the ductus arteriosus, and after passing superficially to the pouch it gained the space between the trachea and osophagus and pursued a normal course to the larynx. The right vagus nerve crossed in front of the aortic arch, supplying a right recurrent laryngeal nerve the course of which was in every way normal. The right vagus as usual passed behind the root of the lung. The thoracic vertebræ described a convexity towards the right side, which fact has also been noted in cases of right aorta by Otto and Turner, and so that it would support the argument of those anatomists who hold that such a curve is not formed by impulses transmitted to it from the aorta. The thoracic duct in its entire extent lay in the left posterior medastinum, at no point passing to the right of the middle line; its termination was normal in all respects. There was no transposition of the viscera.

The case which is here reported is of rare occurrence and represents "atrophy of the fourth left arch with persistence of the right arch and right and left aortic roots." In Sir William Turner's able article in the British and Foreign Medico-Chirurgical Revier, vol. xxx., 1862, he divides the class of case which is being dealt with into three groups according to the variations in the condition of the fitth left vascular arch. In his own words: "It will therefore be advisable to consider them under distinct heads, which will be distinguished from each other by different states of the ductus arteriosus-(1) cases in which the ductus arteriosus is quite patent; (2) cases in which the ductus arteriosus is atrophied to a mere fibrous ccrd; (3) cases in which the ductus arteriosus is altogether absent." This case comes under the second head, and is similar to cases reported by Fiorati and Sandifort, ${ }^{1}$ by Mr. Ewen, ${ }^{2}$ and by Sir William Turner. ${ }^{3}$ A similar case is also figured in Quain's Plates. ${ }^{4}$ The present case corresponds as far as the arterial distribution is concerned with that of Sir William 'Turner. The chief point of difference is in connexion with the left innominate vein. 'This vein bears a relation to the aorta, as will be observed above, which I do not think has been noted in connexion with any irregularities of the aorta or its branches, or even in subjects in which the arterial system is quite normal. The course of the ductus thoracicus, which was wholly in the left posterior mediastinum, is stated by Quain to be a very rare occurrence. In the cases of right aortic arch previously recorded no such course of this duct has been observed, so far as I am aware. The explanation of the arterial irregularities will be readily understood from the accompanying diagram, but the course of the innominate vein cannot be so easily explained. It is probably not a point of much embryological importance, as in the embryonic condition the left innominate vein is merely a communicative branch and not a primary venous trunk.

Some of the points which should be noted in this case are-(1) the arching of the aorta over the right bronchus and its descent for the most part in the right posterior mediastinum; (2) the absence of the innominate artery; (3) the origin of the left subclavian artery from the pouchlike trunk on the left side of the descending aorta; (4) the fact that a vascular circle is formed round the trachea and œesophagus; and (5) the large but impervious ductus arteriosus uniting the pouch and left pulmonary artery.

These points were all noted in Turner's case, but in no cases of right aortic arch has the peculiar course of the left innominate vein under the arch of the aorta been noted as in the present case, and the rare course of the thoracic dnct through the left posterior mediastinum is also worthy of notice.

Glasgow.

Museum Anatomicum, vol. i., p. 273.

Guy's Hospital Reports, 1840. p. 233 B British and Foreign Medico-Chirurgical Review, vol. xxx., p. 1862.

\section{THREE CASES OF ACTINOMYCOSIS.}

\author{
By PENRY W. ROWLAND, M.B. LOND.
}

LATE RESIDENT SURGEON, ROYAL SFA-BATHING HOSPITAL, MARGATE.

THE occurrence of three cases of actinomycosis at one time in a hospital of 150 beds is sufficient reason for reporting them, for the disease is still considered rare.

CASE 1.-A London policeman, aged 22 years, was seized with acute pain in the right iliac region on April 26th, 1900. He was admitted a week later into the Westminster Hospital. After nine days an abscess was opened which was considered to be due to suppurative appendicitis. During the next eight months several incisions were made in the loin and back and in the neighbourhood of the original incision which showed no sign of healing. A dental abscess was also opened. As no evidence of the presence of actinomyces was discovered the disease was at length supposed to be of tuberculous origin. On admission to the Royal Sea-Bathing Hospital, Margate, on Dec. 3rd, several indolent sinuses were present in the right iliac fossa and in the right loin, from which there was a slight amount of discharge containing actinomycotic granules. On the 25th dulness was found on percussion at the right base. Exploration proved the absence of effusion. At the left base auscultation revealed small patches where the lung tissue appeared to be breaking down. A week later cough came on and in a few days two or three pints of purulent sputum containing abundant granules were expectorated without any change in the signs at the right base. The fungus was soon atterwards discovered in pus pressed from a small sinus by the side of a carious bicuspid. During the next few months emaciation steadily increased, accelerated by several attacks of diarrhœea. Blood was present in the stools from time to time, but granules were not detected until August, 1901. Incisions were repeatedly made into new subcutaneous collections of pus in the back. Hæmorrhage was always free on these occasions and tended to persist, especially from cne sinus which passed deeply into the region of the left kidney. The presence of the fungus was readily demonstrated in each new abscess. Pain in the head and across the loins and hips was marked at times and survived all drugs but morphia. Progress was constantly downwards until death occurred on Nov. 20th. Several three-week courses of iodide of potassium were given (90 grains daily) without any evidence of beneficial effect; indeed, the patient's general condition was always worse during the use of this drug. The sinuses were occasionally opened up and pure carbolic acid was applied. Surgical treatment of a more radical nature was not possible.

At the post-mortem examination it was found that the lower lobe of the left lung was congested and that there were old pleural adhesions. In the left lower lobe the pleura was adherent in places where there were several small sinuses connecting abscess cavities in the back with deposits of the fungus close to the surface of the lung. Protruding above the surface in the vicinity were several actinomycotic colonies about a quarter of an inch in diameter. Infection of the lung had apparently taken place through the thoracic wall. The capsule of the left kidney was adherent below and behind, where there was an abscess cavity leading through the left loin to the surface. There were three deposits of actinomyces in the lower third of the organ, the pelvis of which contained pus. The appendix, except for adhesions, was normal. No ulceration was found anywhere in the small or large intestine; a few granules were present throughout, free in the lumen of the bowel. The right iliac abscess was entirely retro-peritoneal and communicated with the sinuses in the back. Advanced lardaceous change was found in the liver, spleen, and kidneys.

CASE 2. - The patient was a London coalheaver, aged 27 years. His illness began in the middle of September, 1900 , with pains in the right side, right loin, and groin whilst walking. Constipation was troublesome. He was admitted to the London Temperance Hospital on Nov. 2nd with an indefinite swelling in the right side of the abdomen. In mid-December there was a definite tumour of the size of a closed fist to be seen and felt in the upper part of the right iliac fossa. On Dec. 27th an incision was made over the iliac crest, which appeared to be bare, and pus escaped. The patient had gained four and a half pounds in weight since admission. There was pyrexia throughout January and steady 
loss of weight. Early in February another fluctuating swelling appeared in the right groin and from this two ounces of pus were evacuated. At the end of February the temperature was always above normal. On the 25th granules were detected and the patient was at once given 60 grains of potassium iodide daily. This dose was soon raised to 90 grains. Two months later he was sent to Margate. Here he continued to lose ground steadily. Several incisions were made in the thigh and back, the escaping pus being highly offensive. After a second attack of diarrhœa the patient became very much worse and died with symptoms of general sepsis on May 24th.

At the post-mortem examination the appendix was found deeply hidden beneath coils of adherent intestine and was surrounded by an abscess extending into the psoas and the muscles of the anterior abdominal wall. This communicated with the sinuses in the groin, right iliac region and back. Septic peritonitis had followed the yielding of adhesions between the coils of bowel, probably during the recent attack of diarrhoa. There were no granules found anywhere except in the pus in the sinuses mentioned above. The macous membrane of the intestine was apparently healthy everywhere. The liver and kidneys showed fatty degeneration : the spleen was considerably enlarged. At the base of the right lung there were recent adhesions and a few ounces of lluid. The latter were caused by perforation of the chest wali from without by an abscess in the back.

CASE 3-The patient, the daughter of an East-end labourer, was $14 \frac{1}{2}$ years of age. She was admitted to the Lundon Hospital on April 6th, 1900. Abdominal pain and vomiting ushered in the disease early in January. The vomiting soon ceased but the pain continued and became worse on March 25th. Dysuria was also present. On admission a hard swelling was found rising up out of the pelvis and reaching to within two inches of the umbilicus, It was situated more on the left than on the right side. There was a small lump in the right hypochondriac region. On examination per vaginam the cervix was found to be drawn up. The swelling appeared to be connected with the uterus. The operation showed the uterus to be normal and the swelling to be confined to the abdominal wall. A hard inflammatory condition was discorered with a little pus. Temporary incontinence of urine followed the operation and several slight fits occurred the next day. Early in May a hard swelling appeared to the right of the median wound. On May 16th cultures were made; no tubercle bacilli were found, nor was there evidence of actinomycosis. A nightly rise of temperature began in June, but there was little change in the patient's general condition. On June 5 th the patient was removed to the Royal Sea-Bathing Hospital. One or two small, almost translucent, granules were found which on microscopic examinalion proved to be actinomyces. Iodide of potassium was immediately given, 60 grains daily, without effect. In July an abscess under the iliac crest was opened but no granules were detected. The patient did not gain weight and remained depressed and ill. In the middle of September she was received back to the London Hospital. A new tumour arose in the right iliac fossa and increased rapidly in size until it reached nearly to the umbilicus. It was apparently closely connectea with the anterior superior iliac spine. On Oct. 1st the anterior abdominal wall was involved. Leave for operation was refused and the patient was discharged. No granules were recognised during her short stay. In December a visit to her home found her under the care of the Canning Town Medical Mission, by whose kindness I was again able to find the fungus in pus from the large abscess which had spontaneously opened. A month or two later an abscess was incised in the right loin. Diarrhoea increased the cachexia and in May the patient died after an illness lasting over two years. Unfortunately, no postmortem examination was made.

The following points seem worthy of note. First, the resemblance between the three cases and some in the series reported by Mr. Godlee in THE LANCET of Jan. 5th, 1901 , p. 3. Secondly, the tendency of the pus to avoid art ificial channels and to track or to gravitate towards the loip : free drainage is insufficient treatment. It is conceirable that light hinders the growth of the "fungus." It would be interesting to know the effect of Roentgen or Finsen rays in cases where the skin is involved. Dental surgeons have sometimes opportunities of early diagnosis upon which the life of the patient depends. In Case 1 it is probable that the jaw was first infected. The necessity for 1 epeated examination of pus in cases of obscure abdominal abscess has frequently been emphasised ; so has the uselessness of iodide of potassium in the later stages of the affection. In a disease of such malignancy surgical treatment should be radical if drug treatment prove unavailing after fair trial

I am indebted to Mr. A. H. Tubby, Sir W. J. Collins, and Dr. G. E. Herman for leave to use notes kindly supplied by Mr. H. Hallilay and Mr. J. $H$ Rhodes. Mr. W. Knight Treves and Dr. A. Rowe were in charge of the patients at the Royal Sea-Bathing Hospital, Margate, and gave me ready permission to publish their cases. To my successor, Mr. R. J. Lambart Sladen, my thanks are due for completing the notes.

Evelina Hospital, Southwark, S.E.

\section{Clinital 筑otes:}

\section{MEDICAL, SURGICAL, OBSTETRICAL, AND THERAPEUTICAL.}

\section{CONCERNING THE AURICULAR REFLEX.}

By Walker Overend, M.A., M.D. Oxon.,

LATE RADCLIFFE TRATELLING FELLOW AND SENIOR PHXSYCIAN TO THE TOT'TENHAM HOSPITAL.

Is a short communication from Mr. E. Donaldson ${ }^{1}$ a reflex movement of the auricle of the ear is described which was observed by him in May, 1902. In a case of apparent hyperæsthesia of the external auditory meatus under his care the insufflation of a powder was followed by a movement of the auricle. The puffing of air alone was also found to produce the same effect. In a paper on the frontal or supra-orbital reflex ${ }^{2}$ I described, incidentally, this movement which, as a matter of fact, I have observed for several years. As therein stated, at times the reflex follows gentle stroking of the skin in front of the meatus-that is, in areas supplied by the auriculotemporal nerve. The attollens aurem is the muscle usually involved, inasmuch as the movement is generally in an upward direction, and the efferent nerve of the reflex arc is the small occipital. I pointed out that the reflex is more readily obtained in adults by tickling the skin just within the external auditory meatus opposite the tragus. The movement is more lively in children and is obtainable in about one-third of the subjects examined. I find that although a puff of air from an indiarubber ear syringe, as Mr. Donaldson states, is quite effectual, still the quick and sudden contact of a camel-hair brush is much more so. To avoid all voluntary movement $\mathrm{I}$ direct that the jaws should be kept firmly and tightly closed.

A proof of the true reflex nature of the movement is the fact that the opposite ear, as a rule, is simultaneously elevated. The effect very soon vanishes; it is not possible to obtain it a second time immediately after the first movement. It is necessary to wait for a few minutes before the reflex can be again elicited. Either the will inhibits the movement, or the muscle, as one might indeed expect, since its fibres are seldom active, becomes fatigued. After some education and practice the response becomes more lively, more pronounced, and easier to obtain.

Clacton-on-Sea.

\section{A NOTE ON THE HISTOLOGY OF X-RAYED LUPUS VULGARIS.}

By George Pernet, M.R.C.S. Eng., L.R.C.P. LoNd., Late Pathologist, hospital For DISFases of THE sKin, BLACKFRIARS, LONDOX.

I AM indebted to Sir Victor Horsley for the opportunity of examining microscopically $\mathrm{x}$-rayed lupus vulgaris tissue, which was freely excised from the frontal region of a man, aged 26 years, for purposes of Wolff grafting-i.e., with the whole thickness of skin down to the subcutaneous fat. The area had been subjected about six months previously to 14 daily consecutive exposures to the Roentgen rays. According to the patient the duration of each exposure was about from 10 to 15 minutes with the tube an inch or two from the

\footnotetext{
1 The LaNCeT, August 23rd, 1902, p. 506

2 The LANCET, Jan. 25th, 1902, p. 219 .
} 